\title{
Reciprocal hemispheric influences on response habituation in the electrodermal system
}

\author{
JOHN GRUZELIER, FRANK EVES, and JOHN CONNOLLY \\ Laboratory of Neuro-Psychophysiology, Department of Psychiatry \\ Charing Cross Hospital Medical School, Fulham Palace Road, London W68RF, England
}

\begin{abstract}
In three investigations, the rate of habituation of phasic electrodermal responses to auditory stimuli and the number of nonspecific responses were correlated with lateral differences in response amplitude. Fast habituation and less frequent responses were associated with higher left- than right-hand response amplitudes, whereas slow habituation and more frequent responding were associated with higher response amplitudes on the right hand. The results indicated a coincidence between the degree of phasic electrodermal activity and reciprocal hemispheric influences, implying hemispheric interactions in mechanisms that control phasic reactivity, habituation, and attention.
\end{abstract}

Habituation to a repetitive stimulus is a primitive form of learning that is thought, inter alia, to enable the organism to attend selectively (Groves \& Thompson, 1970; Horn, 1967; Pakula \& Sokolov, 1973; Pribram \& McGuinness, 1975; Waters, McDonald, \& Koresko, 1977). Here, hemispheric influences on habituation were investigated by measuring bilateral electrodermal orienting activity to repeated tones of moderate and high intensity; we had previously observed small lateral asymmetries in the responses of normal subjects and larger ones in the responses of psychotic patients (Gruzelier, 1973, 1978, 1981; Gruzelier \& Venables, 1973). An association has been drawn between responses that are unrelated to an overt stimulus and sustained, as distinct from selective attention, with a high incidence of responses coincidental with better vigilance (Blakeslee, 1979). Hemispheric influences on sustained attention were therefore explored by recording lateral differences in nonspecific responses.

Electrodermal levels were also examined for lateral asymmetries. Tonic levels of activity have been associated with cognitive and perceptual activation (Kilpatrick, 1972), and a finely tuned balance between the activation patterns of the cerebral hemispheres has been implicated in the control of attention by Kinsbourne (1973), particularly the motor components of the orienting reaction in the lateral plane. At every moment, so the theory goes, we are poised to respond more quickly to the left or to the right, one determinant of which is the dominance in hemispheric activation patterns at the time, which in turn is augmented by the orientational response itself. The direction of orientation is away from the ac-

We are grateful for the assistance of Joe Sergeant and for the statistical advice of K. McRae and U. Jonckheere. tivated hemisphere. In order to determine whether the rate of habituation of the orienting response and the degree of nonspecific responsivity were influenced by tonic arousal properties, the asymmetry in bilateral electrodermal levels was correlated with the asymmetry in response amplitudes to provide a test of Kinsbourne's theory.

Phasic responses to both moderate- and highintensity stimuli were examined in view of the suggestion (Maltzman, Langdon, Pendery, \& Wolff, 1977) that one difference between an active and passive orientation to stimuli lies in hemispheric involvementthe left hemisphere being involved in active attention and the right in a generalized, nonspecific, passive attention. Here, it was difficult, if not impossible, to ignore the intensity of the louder sequence and to adopt a passive attitude toward it.

\section{METHOD}

\section{Subjects}

In the first experiment, subjects were 16 patients admitted to a Copenhagen general hospital for minor surgery involving parts of the body not interfering with electrodermal recording. They were all male and dextral. In the second experiment, there were 62 first-year medical students from a London teaching hospital, and the third involved 31 volunteers from the staff of the same hospital. Both sexes were tested in Experiments 2 and 3 (see Table 1), and the results of the nine sinistral subjects, assessed by a modified Oldfield-Humphrey questionnaire, were also considered as a separate subgroup.

\section{Apparatus}

Beckman silver/silver chloride cup electrodes were attached with Beckman $\mathrm{KCl}$ electrolyte to the medial phalanges of the first and second fingers of both hands. Skin conductance was measured directly by constant current systems connected to a Beckman dynograph in the first experiment and otherwise to a Grass 7D polygraph. The maximum gain setting was $.02 \mu \mathrm{mhos} / \mathrm{cm}$. Stimuli were presented through headphones via tone generators. In three experiments, subjects were presented with a series of 
Table 1

Means and Standard Deviations of the Main Dependent Variables for the Three Groups

\begin{tabular}{|c|c|c|c|c|c|c|c|c|}
\hline & & & & & \multicolumn{4}{|c|}{ Staff* } \\
\hline & \multicolumn{2}{|c|}{ Surgical Patients } & \multicolumn{2}{|c|}{ Students } & \multicolumn{2}{|c|}{$70 \mathrm{~dB}$} & \multicolumn{2}{|c|}{$90 \mathrm{~dB}$} \\
\hline & Mean & SD & Mean & SD & Mean & SD & Mean & SD \\
\hline Trial Until Habituation & 10.88 & 3.11 & 6.840 & 3.55 & 3.720 & 3.91 & 8.200 & 5.76 \\
\hline L1 OR Amplitudes & .48 & 8.14 & .002 & .05 & -.026 & .25 & -.088 & .35 \\
\hline Nonspecific Responses & & & 10.350 & 10.42 & 15.380 & 18.56 & 12.770 & 20.58 \\
\hline L1 N-S Responses & & & -.001 & .01 & .057 & .28 & .062 & .28 \\
\hline
\end{tabular}

${ }^{*} t$ values comparing intensities were all nonsignificant $(t<.86)$ except for an increase in ORs to the 90-dB tones $(t=2.66, p<.01)$.

Table 2

Correlations Between Trials Until Habituation and Lateral Asymmetries in Orienting Response Amplitudes

\begin{tabular}{|c|c|c|c|c|}
\hline Group & Sex & $\mathrm{N}$ & Rho & $\mathrm{p}$ \\
\hline & & \multicolumn{3}{|c|}{ 70-dB Tone Intensity } \\
\hline Surgical Patients & $\mathbf{M}$ & 16 & .53 & .05 \\
\hline Hospital Staff & $\begin{array}{l}M \\
F \\
M+F\end{array}$ & $\begin{array}{l}18 \\
10 \\
28\end{array}$ & $\begin{array}{l}.56 \\
.52 \\
.46\end{array}$ & $\begin{array}{l}.02 \\
.10 \\
.01\end{array}$ \\
\hline Students & $\begin{array}{l}M \\
F \\
M+F\end{array}$ & $\begin{array}{l}37 \\
25 \\
62\end{array}$ & $\begin{array}{l}.46 \\
.13 \\
.39\end{array}$ & $\begin{array}{l}.01 \\
\text { n.s. } \\
.002\end{array}$ \\
\hline All Groups Combined & $\begin{array}{l}M \\
F \\
M+F\end{array}$ & $\begin{array}{r}71 \\
35 \\
106\end{array}$ & $\begin{array}{l}.49 \\
.24 \\
.41\end{array}$ & $\begin{array}{l}.001 \\
\text { n.s. } \\
.001\end{array}$ \\
\hline \multirow[t]{2}{*}{ Sinistrals } & $M+F$ & 9 & .42 & n.s. \\
\hline & & \multicolumn{3}{|c|}{$90-\mathrm{dB}$ Tone Intensity } \\
\hline Hospital Staff & $\begin{array}{l}M \\
F \\
M+F\end{array}$ & $\begin{array}{l}18 \\
13 \\
31\end{array}$ & $\begin{array}{l}.46 \\
.18 \\
.53\end{array}$ & $\begin{array}{l}.06 \\
\text { n.s. } \\
.01\end{array}$ \\
\hline
\end{tabular}

moderate intensity $(70 \mathrm{~dB})$ tones and, in the third, with an additional sequence of more conspicuous tones of higher intensity $(90 \mathrm{~dB})$ and longer duration. The lower intensity tones were of 1-sec duration, $1,000 \mathrm{~Hz}$, with rise and decay times of $250 \mathrm{msec}$, and were presented 13 times in Experiments 1 and 2 and 10 times in Experiment 3 at intervals quasi-randomized between 20 and $40 \mathrm{sec}$. The 90 - $\mathrm{dB}$ tones were similar except that they were $5 \mathrm{sec}$ in length, with the exception of the 11th tone, which lasted for $10 \mathrm{sec}$.

\section{Procedure}

The stimuli were presented under conditions of relaxation with instructions to remain relaxed and ignore the tones. Responses were defined as occurring between .8 and $5 \mathrm{sec}$ poststimulus onset with a minimum amplitude criterion of $1 \mathrm{~mm}$. The criterion of habituation was three successive failures to respond. Responses outside this interval (nonspecific responses) were also scored in Experiments 2 and 3. Levels of skin conductance were calculated at the beginning and end of each tone series and before Tones 5 and 10 . The level was the mean of the four readings.

\section{RESULTS}

Means and standard deviations are shown in Table 1. Correlations between rate of habituation and the lateral difference in response amplitude are shown in Table 2 . The lateral asymmetry is expressed as a laterality index, 2(right - left/right + left), to correct the asymmetry for overall magnitude of responding. In all studies, significant correlations were obtained in the direction of slow habituation and larger right- than left-hand responses. The opposite asymmetry was associated with fast habituation. In other words, the balance in hemispheric influences on electrodermal responses when tipped one way was associated with fast habituation of orienting responses bilaterally and, when tipped the other, was associated with slow habituation.

A similar relation was found between the number of nonspecific responses (elicited by $90 \%$ of subjects) and the asymmetry in their amplitude (see Figure 1). Typically, the number of trials until habituation is positively correlated with the number of nonspecific responses, as shown here in Table 3. Consistent with this, lateral asymmetries in the amplitudes of both orienting and nonspecific responses were positively

$$
\begin{array}{ll}
- \text { MALE } & \text { STUDENTS } \\
\triangle \text { FEMALE } & \text { MEMALE }
\end{array}
$$

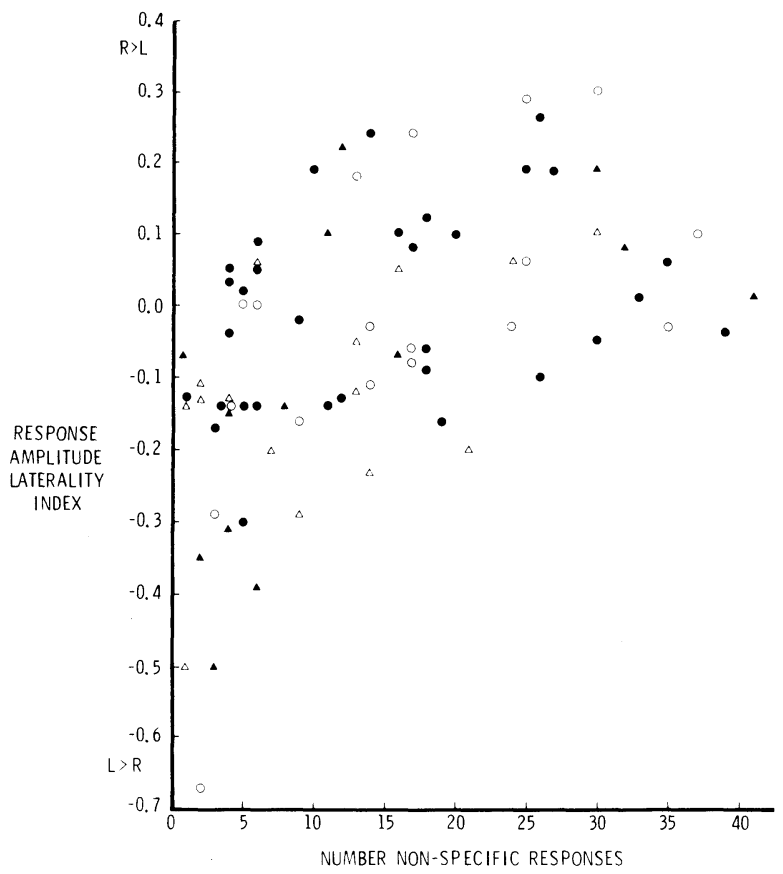

Figure 1. The lateral difference in nonspecific response amplitudes as a function of their incidence. 
Table 3

Correlations Between the Number and Lateral Asymmetries (LI) in Nonspecific Responses (N-SR) and Trials Until Habituation (OR)

\begin{tabular}{|c|c|c|c|c|}
\hline Group & $\begin{array}{c}\text { Tone } \\
\text { Intensity }\end{array}$ & $\begin{array}{c}\text { OR } \\
\text { With } \\
\text { N-SR }\end{array}$ & $\begin{array}{c}\text { LI (OR) } \\
\text { With } \\
\text { (N-SR) }\end{array}$ & $\begin{array}{c}\text { Number } \\
\text { N-SR With } \\
\text { LI (N-SR } \\
\text { Amplitude) }\end{array}$ \\
\hline Hospital Staff & $\begin{array}{l}70 \\
90\end{array}$ & $\begin{array}{l}.84 \\
.76\end{array}$ & $\begin{array}{l}.81 \\
.83\end{array}$ & $\begin{array}{l}.73 \\
.62\end{array}$ \\
\hline \multirow[t]{2}{*}{ Students } & 70 & .79 & .88 & .45 \\
\hline & \multicolumn{4}{|c|}{ Staff and Students } \\
\hline Males & $\begin{array}{l}70 \\
90\end{array}$ & $\begin{array}{l}.69 \\
.76\end{array}$ & $\begin{array}{l}.79 \\
.73\end{array}$ & $\begin{array}{l}.46 \\
.54^{*}\end{array}$ \\
\hline Females & $\begin{array}{l}70 \\
90\end{array}$ & $\begin{array}{l}.78 \\
.66 * *\end{array}$ & $\begin{array}{l}.88 \\
.96\end{array}$ & $\begin{array}{l}.55 \\
.70 \dagger\end{array}$ \\
\hline
\end{tabular}

Note-Tone intensities are given in decibels. All correlations are significant at $p<.001$ unless otherwise indicated.

${ }^{*} p<.05 . \quad{ }^{* *} p<.02 . \quad t p<.01$.

Table 4

Correlations of Asymmetries in Skin Conductance Levels With Asymmetries in Orienting Response Amplitudes and of the Latter (After Partialing Out the Influence of Levels) With Trials to Habituation

\begin{tabular}{lccccc}
\hline & \multicolumn{2}{c}{$\begin{array}{c}\text { Levels LI } \\
\text { With OR LI }\end{array}$} & & \multicolumn{2}{c}{$\begin{array}{c}\text { OR LI With } \\
\text { Habituation }\end{array}$} \\
\cline { 2 - 3 } Group & Rho & $\mathrm{p}$ & & Rho & $\mathrm{p}<$ \\
\hline Surgical Patients & .26 & n.s. & & .49 & .06 \\
Students & .06 & n.s. & & .39 & .002 \\
Hospital Staff-70 dB & .23 & n.s. & .42 & .05 \\
Hospital Staff-90 dB & .32 & n.s. & .49 & .05 \\
\hline
\end{tabular}

Table 5

Correlations Between Habituation and Unilateral Response Amplitude After Partialing Out the Influence of Habituation on Amplitude

\begin{tabular}{lcccccc}
\hline & \multicolumn{2}{c}{ Left Hand } & & \multicolumn{2}{c}{ Right Hand } \\
\cline { 2 - 3 } \multicolumn{1}{c}{ Group } & Rho & $\mathrm{p}<$ & & Rho & $\mathrm{p}<$ \\
\hline Surgical Patients & -.32 & n.s. & & .38 & n.s. \\
Students & -.25 & .05 & & .34 & .01 \\
Hospital Staff-70 dB & -.45 & .02 & & .69 & .001 \\
Hospital Staff-90 dB & -.37 & n.s. & .28 & n.s. \\
\hline
\end{tabular}

correlated, as were the number of nonspecific responses and trials until habituation.

Correlations between lateral asymmetries in electrodermal levels and response amplitudes are shown in Table 4. The relation was insignificant in all experiments. Furthermore, when the influence of levels on responses was partialled out, correlations between the asymmetry in response amplitudes and trials until habituation were virtually unchanged (see Table 4). This suggests that hemispheric influences on phasic orienting and nonspecific responses were independent of influences on levels.
Regarding the effect of increasing tone intensity, which produced more orienting responses, the relation between responsivity and the lateral asymmetry in response amplitudes was not radically altered by the louder tones (see Tables 1-3). The result was confirmed by a t test (see Table 1).

It is noteworthy that instead of disappearing as the rate of habituation increased, the asymmetry reversed. Two explanations are feasible. Either there is a reciprocal relation between the hemispheres in the habituation of orientational reactions or the control of habituation resides in one hemisphere and the reversal in asymmetries stems from the alteration of response amplitudes on one hand only. Correlations were examined between trials until habituation and unilateral response amplitudes were obtained. These are shown in Table 5 after the effect of habituation on response amplitude was partialed out (response amplitudes being, on the average, higher the more responses there are). With neither hand were correlations zero. Correlations with right-hand responses were positive, and those with the left hand were negative. In other words, the effects involved reciprocal interactions between the hemispheres rather than the specialization of one hemisphere.

The inverse relation between the incidence of responses and lateral asymmetries in amplitude occurred in some subjects, particularly with regard to orienting responses. Handedness and sex, factors that have been associated with hemisphere asymmetries of function, were examined in case they were to shed light on the atypical cases. Correlations of a similar order were found in the nine sinistrals with both trials until habituation $(\varrho=.42)$ and nonspecific responses $(\varrho=.50)$. Handedness was therefore not a factor. Considering gender, the effect was found with trials until habituation in all the male groups (combined $\varrho=.49, \mathrm{p}<.001$ ) but, at best, only approached significance in females (combined $\varrho=$ .24; see Table 2); nevertheless, the correlations remained positive in direction. With nonspecific responses, both women and men showed correlations of a similar magnitude. Perhaps an explanation may lie with a reversal of neuroanatomical asymmetries not uncommonly found in both sexes, irrespective of handedness (Le May, 1976). ${ }^{1}$

\section{DISCUSSION}

What is the nature of the hemispheric influences that produce the reciprocal relation and control habituation and the incidence of nonspecific responses? A reciprocity in hemispheric influences for motor components of the visual orientational response has previously been demonstrated between cortical and midbrain areas (Sprague, 1966). As yet, the mediation of hemispheric influences on the elec- 
trodermal orienting response is imperfectly understood. Evidence suggests that these influences may be both excitatory and inhibitory and that ipsilateral and contralateral pathways exist (List \& Peet, 1939; Wang, 1964; Wilcott \& Bradley, 1970). Additionally, the hemispheres may differ in the polarity of their influences on responsivity, the left being predominantly inhibitory and the right excitatory (Heilman, Schwartz, \& Watson, 1978). This difference in polarity, when coupled with the current view (Lacroix \& Comper, 1979) that contralateral inhibitory influences on response amplitude predominate, would explain our correlation as follows. Infrequent responses reflect a dominance of inhibition over responsivity, which is a left-hemisphere polarity. Infrequent responses are coupled with smaller rightthan left-hand responses, which again, in view of the contralateral mediation of inhibitory activity, indicate a dominance of left-hemispheric activity. Conversely, a prepotency of right-hemisphere activity would lead to the opposite relations-namely, more responses and higher right- than left-hand response amplitudes.

In a behavioral context, fewer electrodermal responses and faster habituation combine with better selective attention in the face of distraction, while increased responsivity combines with better sustained attention (Blakeslee, 1979; Waters et al., 1977). Our results are therefore consistent with models of hemispheric specialization in attention (Dimond, 1979) that propose specialization of the left hemisphere in selective attention and of the right hemisphere in sustained attention. Furthermore, the hemispheres interact reciprocally in these functions. The same functional principle could apply to the results of Cohen, Berent, and Silverman (1973). They found that electroconvulsive shock therapy (ECT) to the left hemisphere made subjects more field-dependent, while ECT to the right hemisphere made subjects more field-independent. This was interpreted as evidence of a right-hemisphere functional asymmetry. However, it would be consistent with a hemisphere interaction model-narrowed attention, as in field-independence, indicating left-hemisphere attentional dominance, and broadened attention, as in field-dependence, indicating a right-hemisphere attentional mode.

In this experiment, the series of conspicuous tones increased orienting responsivity. This confirmed that conspicuous tones have a greater impact on attention than do milder tones. Nevertheless, the lateral asymmetries of the group remained unaltered. Our manipulation may have been insufficient to vary attentional strategies. Further experiments would be of interest to determine whether individual differences in electrodermal lateral asymmetries have a bearing on cognitive processes. Instead of the popular practice of explaining, on a post hoc basis, results that diverge from structural models of hemispheric specialization as being due to confounding dynamic influences such as arousal and attention, a priori predictions could be made from electrodermal activity that could then be monitored concurrently.

Kinsbourne's view of a mutual inhibitory balance between the hemispheres in dynamic processes is supported by our data, although to which facets of hemispheric activation this is tied and whether this reflects trait or state variables, or both (cf. Kinsbourne, 1980), remains in doubt. Evidence of important limbic influences on both processes of attention and the electrodermal orienting response and its rate of habituation (Pribram \& McGuinness, 1975) suggest another candidate for exploration. The need is also underscored for considering hemispheric interactions in cognitive theories of the orienting response and attention.

\section{REFERENCES}

Blakeslee, P. Attention and vigilance: Performance and skin conductance response changes. Psychophysiology, 1979, 10, 413-419.

Cohen, B. D., Berent, S., \& Silverman, A. J. Field-dependence and lateralization of function in the human brain. Archives of General Psychiatry, 1973, 28, 165-167.

Dimond, S. Disconnection and psychopathology. In J. Gruzelier \& P. Flor-Henry (Eds.), Hemisphere asymmetries of function in psychopathology. Amsterdam: Elsevier/North-Holland, 1979.

Groves, P. M., \& Thompson, R. F. Habituation: A dual-process theory. Psychological Review, 1970, 77, 419-450.

Gruzelie R, J. H. Bilateral asymmetry of skin conductance, orienting activity and levels in schizophrenia. Journal of Biological Psychology, 1973, 1, 21-41.

Gruzelier, J. H. Bimodal states of arousal and lateralized dysfunction in schizophrenia: The effect of chlorpromazine. In L. C. Wynne, R. L. Cromwell, \& S. Matthysse (Eds.), The nature of schizophrenia: New approaches to research and treatment. New York: Wiley, 1978.

GruzeliER, J. H. Individual differences in hemispheric influences relate to habituation, arousal, introversion, anxiety and psychosis: Review of evidence. Bulletin of the British Psychological Society, 1981, 34, 23.

Gruzelier, J. H., \& Venables, P. H. Skin conductance responses to tones with and without attentional significance in schizophrenic and non-schizophrenic patients. Neuropsychologia, 1973, 11, 221-230.

Gruzelier, J. H., \& Venables, P. H. Bimodality and lateral asymmetry of skin conductance orienting activity in schizophrenia. Biological Psychiatry, 1974, 8, 55-73.

Heilman, K. M., Schwartz, H. D., \& Watson, R. T. Hypoarousal in patients with the neglect syndrome and emotional indifference. Neurology, 1978, 28, 229-232.

HorN, G. Neuronal mechanisms of habituation. Nature (London), 1967, 215, 207-211.

Kilpatrick, D. G. Differential responsiveness of two electrodermal indices to psychological stress and performance of a complex cognitive task. Psychophysiology, 1972, 9, 218-226.

Kinsbourne, M. The mechanism of hemispheric control of the lateral gradient of attention. In S. Kornblum (Ed.), Attention and performance IV. London: Academic Press, 1973.

Kinsbourne, M. A model for the ontogeny of cerebral organisa- 
tion in non-right-handers. In J. Herron (Ed.), Neuropsychology of left-handedness. London: Academic Press, 1980.

LACroix, J. M., \& Comper, P. Lateralization in the electrodermal system as a function of cognitive/hemispheric manipulations. Psychophysiology, 1979, 16, 116-129.

LE MAY, M. Morphological cerebral asymmetries of modern man, fossil man, and nonhuman primates. Annals of the New York Academy of Sciences, 1976, 280, 349-366.

List, C. F., \& PeEt, M. M. Sweat secretion in man. V. Disturbances of sweat secretion with lesions of the pons, medulla and cervical portion of cord. Archives of Neurology and Psychiatry, 1939, 42, 1098.

Maltzman, I., Langdon, J. B., Pendery, M., \& Wolff, C. Galvanic skin responses: Orienting reflex and semantic conditioning and generalization with different unconditional stimuli. Journal of Experimental Psychology: General, 1977, 106, 141-171.

Pakula, A., \& Sokolov, E. Habituation in gastropoda: Behavioural, interneuronal, and endoneuronal aspects. In H. V.S. Peeke \& J. Herz (Eds.), Habituation. II. Physiological substrates. London: Academic Press, 1973.

Pribram, K. H., \& McGuinness, D. Arousal activation and effort in the control of attention. Psychological Review, 1975, 82, 116-149.
Sprague, J. M. Interaction of cortex and superior colliculus in mediation of visually guided behaviour in the cat. Science, 1966, 153, 1544-1547.

WANG, G. N. The neural control of sweating. Madison: University of Wisconsin Press, 1964.

Waters, W. F., McDonald, D. G., \& Koresko, R. L. Habituation of the orienting responses: A gating mechanism subserving selective attention. Psychophysiology, 1977, 14, 228-236.

WilcotT, R. C., \& Bradley, H. H. Low frequency electrical stimulations of the cat's anterior cortex and inhibition of skin potential responses. Journal of Comparative and Physiological Psychology, 1970, 72, 351-355.

\section{NOTE}

1. A subsequent investigation of personality correlates showed that subjects who combined slow habituation with larger lefthand responses were higher on questionnaire scores of anxiety than were the other subjects (Gruzelier, 1981).

(Manuscript received September 30, 1980; revision accepted for publication May 12, 1981.) 